\title{
Increasing the efficiency of land use in real property complexes development projects
}

\author{
Sergey Nosov ${ }^{1}$, Boris Bondarev ${ }^{2}$, Evgeny Venevtsev $^{1}$, Tatiana Svintsova $^{1}$, and Sergey \\ Eroshkin ${ }^{3, *}$ \\ ${ }^{1}$ Plekhanov Russian University of Economics, 36, Stremyannoy Pereulok, 117997, Moscow, Russia \\ ${ }^{2}$ Peoples' Friendship University of Russia, 6, Miklukho-Maklaya st., 117198, Moscow, Russia \\ ${ }^{3}$ Russian State Social University (RSSU), 4, build.1, Wilhelm Pieck st., 129226, Moscow, Russia
}

\begin{abstract}
The relationship between the development of the city 's transport infrastructure and urban land use is a pressing problem in the territory development of any metropolis. Addressing this challenge requires the creation of new tools and mechanisms. Transport infrastructure is the main component of the entire infrastructure of any city, affecting the social, economic and environmental efficiency of urban land use. Therefore, the authors, choosing transport infrastructure as the object of the research, analyze the patterns that arise during its development on the conditions of the entire urban land use. Methods such as calculationgraphical, analysis and synthesis, abstraction method, etc., are used. The authors analyze management methods of urban transport systems as part of real property complexes. The ecological and economic justification of development projects for the real property complex is proposed as a tool for determining perspective directions and mechanisms for increasing the efficiency of land use.
\end{abstract}

\section{Introduction}

In recent decades, the world has witnessed an accelerated process of urbanization of the territories. Urban areas are actively expanding, urban development is compacting, so urban lands are playing an increasing role in the economic development of countries. The increase in urban population density is accompanied by an increase in anthropogenic environmental pressure and an increase in the intensity of natural resource consumption. The main problem of cities is limited land resources.

Currently, the issues is actively studied for solving problems of urban development, and first of all, improving the layout and development of the territory, urban zoning. At the same time, insufficient attention is paid to problems of urban land use efficiency, peculiarities of urban land use, ecological justification of preservation of urban natural complex. There is a growing need for ecological and economicjustification for the development of the transport real property complex, which forms for the functioning basis of urbanized territories.

\footnotetext{
* Corresponding author: EroshkinSIu@rgsu.net
} 
The growth of cities, the development of their territories, the preservation of the ecological balance of urban natural complexes, as well as the impact of infrastructure facilities on the state of the environment were addressed by such scientists as Stefan M. Knupfer, Vadim Pokotilo, Jonathan Woetzel , Vasenev V.I., Stoorvogel J.J., Leemans R., Valentini R., Hajiaghayeva R.A. [1,1], Mikheeva A. S., Ayusheeva, S. N. [2], Medvedeva O. E., Trofimenko Yu. V. [4]. Problems of land use development, infrastructure and management of real property complex in terms of urbanization in relation to transport systems are considered in the works of O. A. Antipov, B. E. Bondarev, S. I. Nosov, L. M. Papikian[4], E. O. Koncheva [5], Vukan R. Vuchic [7].

Modern problems of project management in the investment and construction sphere, peculiarities of their ecological and economic assessment are considered in the works of V.I. Resin, I.L. Vladimirova, A.N. Dmitriev, E.P. Pankratov[8,9], O. E. Medvedeva [9,10] and others. Tools for taking into account both economic and environmental factors in the development of urban transport infrastructure are provided, for example, in the relevant methodological documents of the UK, USA [12] and EU countries [13], and also the world Bank [14].

At the same time, it should be noted that the available tools are general in nature and have not been worked out in detail despite the fact that Russia has approved guidelines for evaluating the effectiveness of investment projects at the Federal level. There are examples of evaluating infrastructure investment projects at the regional level. However, many problems of forming economic mechanisms for regulating land use and improving the efficiency of accounting for land resources as conducting ecological and economicjustification of development projects for the development of real property complexes have not been sufficiently studied.

\section{Materials and Methods}

\subsection{The role of land use in urban infrastructure development}

Russian lands, forests, subsoil and water are the world's most powerful natural resource potential and the main competitive advantage of the Russian state's economic development over other countries. In this regard, the organization of rational use and protection of land should become a source of development and prosperity of the country in the $21^{\text {st }}$ century. The earth is the main environmental component of nature, the material component of people's lives and activities, the base for the placement and development of all sectors of the economy.

Rational land use is the use of land that meets the overall interests of society, owners and users of land, providing the most appropriate and cost-effective consumption of its useful properties in the production process, optimal interaction with the environment, protection and reproduction of land resources.

Large cities are the main centers of human activity. They play a leading role in the socio-economic development of the country. The industrial, social, educational and cultural activities of the society are concentrated in the cities and surrounding territories. At the same time, a high concentration of population, vehicles, industrial and residential development creates an environment that is radically different from the natural environment, so-called urbanization.

More intensive development of the city's housing, social, transport and other infrastructure is required due to the growth of cities. As the world's population increases, man-made pressure on the environment will also increase, including a rise in the 
concentration of pollutants in the air, water and soil, and the expansion of built-up areas mainly through the development of agricultural and forest land.

Compliance with the principles of rational environmental management and, first of all, rational land use, becomes important especially in large cities, as the process of urbanization contributes to the aggravation of all types of environmental problems. Effective management of the large cities resources contributes to the sustainable development of the whole country's economy.

Despite the fact that each city has its own unique history, natural environment, cultural traditions and other distinctive features, certain groups of cities have similar problems. For modern large cities, the problem of insufficient natural and spatial resources is particularly relevant. The growing population of cities increases the demand for natural resources, the availability of which is decreasing accordingly. In this regard, for the further development of cities, it is necessary to find compromises and balanced solutions in terms of ensuring environmentally friendly and comfortable living of residents and sustainable consumption of limited natural resources, especially land resources. Therefore, the issues of managing existing land resources are the most acute.

The urbanized lands act as the basis of all activities. These lands are a reserve of urban spaces beyond which the functioning and sustainable development of the city is impossible. Spatial characteristics of urban land are most important, in the same time as soil fertility is important in the forest industry and agriculture.

However, the development of urban spaces is inevitably accompanied by the destruction and degradation of land cover.

The main cause of land degradation in the city is the coating of land with impermeable asphalt concrete materials in the construction of housing, roads, industrial and other urban facilities. Sealing of urban areas is the main cause of urban soils degradation, disruption of urban ecology. Sealed land plots have altered air, water and heat regimes, disturbed ecosystems. The share of sealed areas in major cities of the world exceeds $60 \%$, while in central areas the share of such areas increases to $95 \%$.

Unsealed plots of land are usually under the objects of greening the territory. It is necessary to carry out an accomplishment of territory and landscaping of urban spaces. These processes have a positive impact on the sanitary, architectural and planning, social and aesthetic characteristics of the city.

Analyzing data of analysts [16] comparing 12 comparable megacities of the world, it can be seen that the area of green natural and recreational objects per capita of Moscow in 2019 is at the level of Hong Kong and Berlin, while Beijing, Shanghai and Seoul take the lowest positions of the rating. However, all cities have long-term greening programs for their territories. Green plantations form parks, gardens, etc. make the area more attractive and more convenient for the population, that is positively affects the land use of the area and increases the cost of real estate.

Due to the insufficient amount of ground space in modern cities, their successful development will be connected with the development and implementation of design solutions aimed at the most rational use of all types of available spaces, including ground, above-ground (trestle), surface and underground.

Thus, current trends in the development of large cities determine their limited spatial resources. The main value of the land as a natural resource in the conditions of the modern city lies in its essence as a spatial basis for carrying out various activities and placing urban objects. In case of dense development and relatively small size of land plots, underground and above-ground space has special significance.

It is necessary to maintain a strict balance of the use of territories in order to create conditions for the effective functioning of natural and technical systems that ensure the high quality of life of the urban population. 
The city's territory development leads to an increase in the need for additional space for accommodation construction of residential, commercial, social and other objects. At the same time as the development of land use in the area, the increase of floors and the construction of new buildings, the volume of passenger transport are also increasing. Transport infrastructure for personal and public transport also should be developed as the additional passenger transport is required. Additional space is nessesary to meet transport needs. Thus, there is a demand to differentiate limited urban spaces for transport and nontransport needs.

It is unacceptable that transport dominates other activities, and its intensive development should not negatively affect the ecology of the city and the quality of life. In addition, given the substantial requirements for transport facilities, and limited areas of the city in dense areas, there is competition for available space between the two functions of the city's basic activities, such as work, trade, service, housing and leisure, and transport.

From the point of view of land use optimization, a rational approach to the use of land in the construction of transport facilities is as follows:

- use of least value agriculture land for transport facilities, which are neither particularly valuable land nor specially protected natural areas;

- minimizing the land required for transport by improving vehicle productivity and engineering solutions at transport facilities.

The use of the land at the disposal of the city and the nature of urban design play a decisive role in the choice of the direction of transport systems development. For example, in areas with multi-storey development and few parking spaces, the development of highspeed public transport plays a decisive role, while the area designed to accommodate private houses remains an increased demand for private vehicles.

The need for close interaction and balance between land use and the environmentally sound development of the city's transport infrastructure is due to the fact that changes in the transport system have an immediate impact on land use and have long-term positive or negative consequences.

Street-road network and linear objects of public transport form the structure of the city, its framework. Their placement strengthens the physical location of all other facilities located on the urbanized area for years and decades to come, so planning for their placement requires a particularly responsible approach. In general, it can be noted that transport development is the cause of land use development, and the opposite is true. Improvement of transport infrastructure is a key factor in the development of both individual districts and the city as a whole. The creation of a transport infrastructure facility increases the intensity of the development of other infrastructures in the region and affects the location of urban facilities. The development of the area requires the development of transport routes. Thus, the functioning of all facilities is related to their transport accessibility.

Publications on urban land administration define the concept of "real property management". As the city's land is inextricably linked to other types of movable and immovable property.

"Real property complex" is an integral concept combining in its content the definition of the term "real" as a socio-economic essence of real estate and the term "property" as a category expressing a set of property rights and obligations belonging to a natural or legal person, or a set of things, for example, the subject of property employment, purchase and sale, lease, pledge, etc. The real property complex is considered as a set of all land resources in a dynamic variety of different forms of ownership and types of land use, administrative and economic structures, legal entities and individuals connected with legal relations over the distribution and use of land. 
From an economic point of view, the real property complex is understood as a combination of land and other related resources in a variety of forms of ownership and management, taking into account the uniqueness of the land as a natural resource and the basis of the existence of mankind, the productive forces of society. A real property complex is a collection of land and other property with a certain functional purpose. At the same time, the earth is not just a functional part of this population, but its base, a system-forming element.

A mandatory element of any real property complex is a land plot. The complex also includes other real estate objects; Movable property objects belonging to fixed assets; Movable property relating to revolving funds.

In order to solve the problem of ecological and economic justification of the land use development occupied by transport facilities, we propose to allocate in a separate category another type of such complex - transport real property complex. By transport real property complexes we mean real property complexes intended for realization of tasks of transport support of the population.

The structure of transport real property complex is proposed:

1) set of land plots, different in the form of ownership, purpose, value and volume of payments for them, used to ensure the operation of the transport system;

2) inextricably connected with land plots real estate objects of different levels of accommodation:

- tunnels, underground structures, etc.;

- land linear objects (roads, separate public transport routes, etc.);

- structures for above-ground arrangement of linear objects (bridges and trestles);

- other buildings and structures ensuring the operation of transport (parking, depot, garages, ventilation shafts, stations, ground buildings of crossings, etc.);

3) vehicles (public rolling stock, automobiles, etc.).

\subsection{Carrying out ecological and economicjustification}

It is advisable to manage the development of infrastructure from the position of the project approach of managing the real property complex development. However, a mechanism for analysing the long-term environmental impact of the project is not sufficiently developed to provide indicators such as the benefits of increased economic activity and land use development resulting from the project or the costs of eliminating environmental damage caused by the construction and operation of the transport facility.

The preparation of an ecological and economicjustification will allow to determine the costs and benefits of transport projects for society, state and business, as well as help to find a balance of interests, avoid negative consequences from the implementation of the project and optimize the necessary volume of investments.

These provisions are reflected in the applied methods of foreign countries and are partly present in certain domestic legal and regulatory documents and recommendations, which will be considered in detail. It should be noted that there is currently insufficient attention to this issue. Therefore, we consider it relevant to analyze the existing methods of assessing investment and construction projects, which include consideration the above-mentioned factors. There should also be developed an integrated approach to the preparation of ecological and economicjustification for the implementation of transport projects that include an assessment of the territorial factors of the urban environment.

The most common applied methods for evaluating the effectiveness of investment and construction projects in the field of transport, used abroad, include the methods of the UK, the US and the European Union, as well as the world Bank. Let's look at the main ones: 
1) Transport project assessment system developed by the UK Department of transport "WebTAG" (Transport Appraisal Guidance). The assessment is carried out on four main parameters: impact on the economy, environment, society and the state budget.

2) The widely used document is the Methodological Recommendations of the U.S. Department of Transportation "to justify the public effectiveness of TIGER road development projects" [12], which are used on a competitive basis in the process of state investment in transport projects. The projects proposed for consideration should be aimed at achieving long-term social and environmental objectives and assessed by their impact on the economy and the promotion of innovation.

3) Separately, it is worth noting the project "HEATCO" (Developing Harmonised European Approaches for Transport Costing and Project Assessment) [13]. This project aims to unify approaches to assessing the effectiveness of transport projects in European countries. According to the above-mentioned document, in order to carry out the "costs benefits" analysis, the European Union most often takes into account the cost of implementing the project, the cost of maintaining the object in a standard state, limiting the movement of vehicles during the project implementation, reducing the cost of operating vehicles, reducing the cost of transporting goods, reducing travel time for passengers, the amount of fare, the impact on safety, the impact on noise levels, the impact on air pollution, and the impact on climate change.

4) Approach of the world Bank - "Notes on the Economic Evaluation of Transport Projects" [14]. This document describes the basic principles and approaches to assessing the cost-effectiveness of transport infrastructure development projects, which the World Bank proposes to use when evaluating projects in both developed and developing countries of the world. In the document presented on the website, the calculation of the economic efficiency of the transport project includes: a gain for users of transport infrastructure, a gain for operators, carriers and public sector organizations, a gain due to an improvement in the environment, a decrease in the number of road accidents and others

Despite the common practice of consideration a wide range of factors for the evaluation of transport projects abroad, it can be said that in Russia such a comprehensive assessment is hardly carried out. The legislation does not clearly state the need for a detailed analysis of environmental factors in the preparation of projects, and the available methodological recommendations do not fully take into account the entire impact of the transport complex on the natural environment and society. To some extent, the need for ecological and economicjustification of projects is enshrined in the Methodological Recommendations for Assessing the Effectiveness of Investment Projects.

Projects for new construction and reconstruction of transport and other infrastructure, which have a direct impact on improving the quality of life in this area, should be classified as infrastructure investment projects.

The efficiency of the project includes commercial and social components. Indicators of social efficiency take into account the social and economic impact of projects on society: immediate results and costs of the project, as well as costs and results in related sectors of the economy, environmental, social and other non-economic effects. It is recommended to consider the impact of the project implementation on the activities of third-party enterprises and the population, including the change in the market value of real estate due to the project implementation, the impact of the project implementation on the health of the population, etc.

Despite the recommendations in the law on the preparation of such assessments of ecological and economiceffects, there are no formal requirements and methods for their implementation at the federal level, but there are regional recommendations as well as research results in the scientific literature. The example of one of the approved methods is the Methodological Guidelines for Assessing the Social and Economic Efficiency of 
Investment Projects in the Field of Transport Infrastructure Development, approved in Moscow, as well as a draft Methodology for assessing the socio-economic effects of implementing infrastructure projects with state support.

Methodological guidelines establish the procedure for evaluating investment projects in the field of capital construction, reconstruction, technical equipment of transport and other infrastructure, partially or fully financed from the regional budget.

Methodological approaches for carrying out ecological and economicassessment are considered in the Temporary Methodological Recommendations for assessing ecological and economicefficiency of projects of the planned economic activity (not officially approved), as well as the main ideas were developed in subsequent scientific research [15].

The "Moscow metro", as an object of testing the developed approach, was considered in the form of a transport real property complex. For this purpose, there was carried out a comprehensive analysis of the urban spaces occupied by it, the number and area of land plots issued for the placement of objects of various purposes, ensuring the possibility of operation of the metro system. The main ecological and economicfactors of metro operation are considered.

\section{Results}

According to the analysis, we can conclude that nowadays the mechanism for ecological and economicevaluation of investment projects in the field of transport construction has not been fully studied and has not been implemented in practice but it is a key factor in the development of the country's economy. After analyzing the foreign practice of evaluating the effectiveness of transport projects and domestic documents for evaluating investment projects, it is advisable to develop and implement a separate regulatory document. This document will contain recommendations for preparing an ecological and economicjustification for transport infrastructure development projects.

The authors propose to conduct the ecological and economicjustification by comparing projects with their net present value, return on investment and internal rate of return. The calculation of these indicators must necessarily include cost-benefit criteria calculated using special formulas. The approach meets the principles of rational and effective environmental management. The methodology allows to take into account, first, the cost of consumed natural resources and the change in their cost as a result of the project implementation. In this case, the main natural resources are land resources, as well as spaces under and above the surface of the earth. Second, the methodology will allow a preliminary assessment of the potential damage to the environment.

The ecological and economicjustification using this methodology will allow to include in the analysis and justification a wider range of factors in the selection of investment projects for the construction of transport infrastructure facilities and, accordingly, to determine in a comprehensive, more objective manner the effectiveness of the projects implemented, taking into account the possibility of reducing their cost and optimizing land use.

The inclusion of a wide range of social and environmental aspects beyond economic effects in the project's estimated costs and benefits is a feature of the project evaluation papers reviewed. We will classify the main indicators considered by these documents by their classification as cost factors directly related to the construction and operation of the transport facility and natural, related to the impact on the environment and consumption of natural resources. 
Table 1. Classification of ecological and economicjustification of transport infrastructure projects.

\begin{tabular}{|l|l|}
\hline \multicolumn{1}{|c|}{ Type } & \multicolumn{1}{c|}{ Factors } \\
\hline Economic & $\begin{array}{l}\text { - design and survey, construction and installation works (capital } \\
\text { expenditures for project implementation); } \\
\text { - the cost of maintaining the object in the standard state } \\
\text { (operating costs); } \\
\text { - compensation for lost profits and damage to the owners of } \\
\text { property seized for the purpose of construction of the object, as } \\
\text { well as compensation for other possible restrictions related to } \\
\text { construction; } \\
\text { - costs for the operation of facilities; } \\
\text { - revenue from passenger transportation; } \\
\text { - income from other activities (placement of revenue objects); } \\
\text { - the cost of consumption of urban space; } \\
\text { - change in the value of land resources. }\end{array}$ \\
\hline - noise and vibration pollution; \\
- air pollution; \\
- pollution of soil and water resources; \\
- changing the landscape, urban landscape (aesthetic impact); \\
- the fragmentation of the landscape (barrier effect); \\
- seized the soil for the purpose of placing underground \\
facilities and soil disruption; \\
- soil degradation from sealing land plots with linear transport \\
objects.
\end{tabular}

We propose to implement the integrated economic effect of the transport project as part of the ecological and economicjustification on the basis of the following model:

$$
\mathrm{EE}_{\text {tr }}=\mathrm{I}_{\mathrm{tr}}+\mathrm{D} \Delta_{\text {r.est }}+\mathrm{I}_{\text {pl r.est }}-\mathrm{C}_{\text {con }}-\mathrm{C}_{\text {comp }}-\mathrm{C}_{\text {oper }}-\mathrm{C}_{\text {space }}-\mathrm{C}_{\text {noise }}-\mathrm{C}_{\text {vibr }}-\mathrm{C}_{\text {subsoil }}-\mathrm{C}_{\text {land degr }} \text {, }
$$

where:

$\mathrm{I}_{\mathrm{tr}}$ - Income from the transport facility for the period, (rubles/period);

$\mathrm{D} \Delta_{\text {r.est }}-$ Difference from the change in the value of real estate in the area adjacent to the transport facility, (rubles);

$\mathrm{I}_{\mathrm{pl} \mathrm{r.est}}$ - Income from the placement of real estate objects above or under the transport object, (rubles/period);

$\mathrm{C}_{\text {con }}$ - Total capital costs for the construction of the facility, (rubles);

$\mathrm{C}_{\text {comp }}-$ Costs for compensation of losses of right holders of real estate objects, (rubles);

$\mathrm{C}_{\mathrm{oper}}-$ Sum of costs for operation of the facility, (rubles/period);

$\mathrm{C}_{\text {space }}-$ Cost of space required for transportation, (rubles);

$\mathrm{C}_{\text {noise }}$ - Noise removal costs, (rubles);

$\mathrm{C}_{\mathrm{vibr}}-$ Costs of vibration impact elimination, (rubles);

$\mathrm{C}_{\text {subsoil }}$ - Costs of damage to the subsoil, (rubles);

$\mathrm{C}_{\text {land degr. }}-$ Costs of land degradation from land sealing by linear transport facilities, (rubles);

Indicators such as net present value (NPV), return on investment ratio (BCR), internal rate of return (IRR), and return on investment period $(\mathrm{PB})$ can be used to further determine the effectiveness of the project.

\section{Discussion}

As a result of the study, it was revealed that the environmental problem is particularly acute for modern megacities, including Moscow. In conditions of insufficient natural and spatial resources, it is necessary to improve the system of land use management in the city. Land 
resources are the main element of urban space, which has environmental characteristics and soil cover.

It is proved that the development of urban spaces, as a rule, causes soil disturbance and degradation on urbanized lands, due to the sealing of urban areas as a result of covering the land with impermeable materials during the construction of transport and other urban infrastructure. It is necessary to keep records of sealed and unsealed urban spaces, along with an indicator of the density of the building, in order to balance and organize the improvement and greening of urban areas. These territories have a favourable influence on sanitary and hygienic, architectural and planning, social and aesthetic indicators of the territory.

Use of underground and above-ground space for accommodation of structures and communications in conditions of high density of urban development and limited ground spaces has a special significance.

The development of transport contributes to the more dynamic development of the territory and the intensification of urban land use. Improved land use leads to the transport necessity, which requires a balance between the limited space available for transport and non-transport needs.

\section{Conclusions}

It has been established that the organization of ecological and economically justified land use of the transport real property complex is the main aspect of the interaction of transport development management and compliance with environmental management. From the point of land use view, a rational approach to the use of land in the placement of transport facilities is to use the least valuable land for transport facilities and to minimize the spaces required for transport. This is achieved by increasing the productivity of vehicles and the efficiency of engineering solutions at transport facilities.

Based on the calculations, it is proved that a comprehensive accounting of all long-term costs and benefits of underground and above-ground placement types of transport real property complex objects characterizes them as the most ecological-cost-effective. Calculations have shown that the placement of linear objects by an overpass or underground method is more effective than the ground method of location by $274.0 \%$ and $629.4 \%$, respectively (in terms of the difference in annual costs and benefits).

The publication has been prepared with the support of the "RUDN University Program 5-100" and Russian Foundation for Basic Research (RFBR) within the scientific project "Development of methodology for rural territories management based on identification of especially valuable land and development of tourism in digital economy" No. 19-010-00837.

\section{References}

1. S.M. Knupfer, V. Pokotilo, J. Woetzel, Elements of success: Urban transportation systems of 24 global cities (McKinsey Center for Future Mobility, 2018)

2. V.I. Vasenev, J.J. Stoorvogel, Journal of Cleaner Production 170, 69 (2018) https://doi.org/10.1016/j.jclepro.2017.09.161

3. A.S. Miheeva, S.N. Ayusheeva, Economic instruments for justifying environmental investments: monograph (Russian University of Economics, Moscow, 2017) https://search.rsl.ru/ru/record/01009404120 
4. A.I. Artemenkov, O.E. Medvedeva, Intern. Sc. and Pr. J. "Bulletin of The Financial University" 4, 45-56 (2015) https://www.elibrary.ru/download/elibrary_ 24099639_34361855.pdf

5. B. Bondarev, S. Nosov, L. Papikian, Intern. Sc. Conf. SPbWOSCE-2018 110, 8 (2019) https://doi.org/10.1051/e3sconf/201911002001

6. E.O. Koncheva, Public administration J. 52, 163-174 https://www.elibrary.ru/download/elibrary_24896744_78474709.pdf

7. V.R. Vuchic, Transportation for Livable Cities (Routledge, London, 2017)

8. V.I. Resin, Y.S. Popkov, Macro-system models in city development management: monograph (Galaktika, Moscow, 2010)

9. V.I. Resin, Management of Major City Development (Golos, Moscow, 1996)

10. O.E. Medvedev, A.I. Artemenkov, P.V. Medvedev, Assessment Issuses J. 3(81), 2-14 (2015) https://elib.pstu.ru/vufind/EdsRecord/edselr, edselr.24913266

11. O.E. Medvedeva, Environmental impact. assessment J. 6, 100-141 (2004) https://ekollog.ru/metodicheskie-rekomendacii-po-osushestvleniyu-ekologoekonomic.html

12. U.S. Department of Transportation website. BUILD Discretionary, http://www.dot.gov/tiger

13. University of Stuttgart website. Project «HEATCO», https:// www.ier.unistuttgart.de/publikationen/pb_pdf/Bickel_HEATCO_presentation.pdf

14. The World Bank website, http://documents.worldbank.org/curated/en/ 928301468762905413/pdf/Cities-on-the-Move-A-World-Bank-Urban-TransportStrategy-Review.pdf

15. A.O. Krivonosov, Young scientist J. 3, 74-76 (2018)

16. PwC website, https://www.pwc.ru/en/publications/collection/quality-of-living.pdf

17. O. Kozhevina, N. Salienko, V. Kluyeva, S. Eroshkin, Advances in Intelligent Systems and Computing 983, 247-256 (2019) https://doi.org/10.1007/978-3-030-19868-8_25

18. T.Kh. Usmanova, S.Y. Eroshkin, Proceedings of 2017 10th International Conference Management of Large-Scale System Development, MLSD (2017) doi: 10.1109/MLSD.2017.8109700 